\title{
ANALISIS KUALITAS LAYANAN PERPUSTAKAAN ALTERNATIF WILAYAH SELATAN KOTA YOGYAKARTA DENGAN MODEL SERV- QUAL
}

\author{
Lia Yuliana \\ Universitas Negeri Yogyakarta \\ e-mail: lia_yuliana@uny.ac.id \\ Fauziah Khusnullaili \\ Universitas Negeri Yogyakarta
}

\begin{abstract}
Abstrak:
Perpustakaan Alternatif Wilayah Selatan Kota Yogyakarta merupakan salah satu perpustakaan umum yang ada di Yogyakarta. Penelitian ini bertujuanmengetahui kualitas layanan Perpustakaan Alternatif Wilayah Selatan Kota Yogyakarta berdasarkan model Servqual. Jenis penelitian yang digunakan yaitu penelitiankuantitatif dengan pendekatan deskriptif. Populasi penelitian ini adalah pemustaka di Perpustakaan Alternatif Wilayah Selatan Kota Yogyakarta. Penentuan jumlah sampel menggunakan rumus Slovin dengan tingkat kesalahan 0,1 dan $n=4.639$. Jumlah sampel penelitian yaitu 99 responden dengan penentuan responden menggunakan teknik random sampling. Teknik pengumpulan data dengan metode angket, observasi, dokumentasi, dan wawancara. Teknik keabsahan dan analisis data menggunakan uji validitas dan reliabilitas dengan aplikasi SPSS 19.0 dan Microsoft Excel 2010, berikutnya dianalisis secara deskriptif kuantitatif. Hasil penelitian menunjukkan bahwa tingkat kepuasan pemustaka terhadap kualitas layanan di perpustakaan Alternatif Wilayah Selatan Kota Yogyakarta pada lima variable yakni bukti fisik sebesar 81 , kehandalansebesar $89 \%$,ketanggapan sebesar $90 \%$, jaminan sebesar $81 \%$ serta empati sebesar $84 \%$. Sedangkan rata-rata kepuasan pada kelima aspek yakni $84 \%$ dengan kategori sangat puas.
\end{abstract}

Kata Kunci: kualitas layanan, layanan perpustakaan umum, perputakaan pevita

\begin{abstract}
:
Alternative Library for the Southern Region of Yogyakarta city is is one of the public libraries in Yogyakarta.This study aims to determine the quality of alternative library services for the Southern Region of Yogyakarta City based on the Servqual model. The type of research used is quantitative research with a descriptive approach. The population of this research is library users of the Southern Region of Yogyakarta Alternative Library. The number of research samples is 99 respondents with the determination of respondents using random sampling techniques - the data collection techniques using questionnaires, observation, documentation, and interviews. Validity and data analysis techniques used using SPSS 19.0 and Microsoft Excel 2010, then analyzed descriptively quantitatively. The results showed that the satisfaction level of visitors to the quality of service in the Alternative Library of the Southern Region of Yogyakarta City on five variables, namely physical evidence of 81 , reliability of $89 \%$, the responsiveness of $90 \%$, assurance of $81 \%$ and empathy of $84 \%$. While the average satisfaction in the five aspects is $84 \%$ with the very satisfied category.
\end{abstract}

Keywords: service quality, public library service, pevita library

\section{PENDAHULUAN}

Perpustakaan merupakan institusi pengelola koleksi karya tulis, karya cetak, dan/atau karya rekam secara profesional dengan sistem yang baku guna memenuhi kebutuhan pendidikan, penelitian, pelestarian, informasi, dan rekreasi para pemustaka. Hal tersebut tertuang dalam Undang-Undang Nomor 43 Tahun 2007 pasal 1 ayat (1) tentang Perpustakaan. Selain itu, dipaparkan dalam Penjelasan Umum Undang-Undang Nomor 43 Tahun 2007 tentang Perpustakaan, bahwa Perpustakaan sebagai bagian dari masyarakat dunia ikut serta 
Lia Yuliana dan Fauziah Khusnialli

Analisis Layanan Perpustakaan Alternatif

Wilayah Selatan Kota Yogyakarta dengan Model Servqual

membangun masyarakat informasi berbasis teknologi informasi dan komunikasi. Berdasarkan pendapat Mortimer ${ }^{1}$ yang menyebutkan bahwa perpustakaan dapat dikelola secara umum oleh badan publik, institusi, badan hukum, atau individu pribadi. Koleksi dan layanan publik serta institusional dapat digunakan oleh masyarakat umum. Perpustakaan terbagi menjadi beberapa jenis, sesuai dengan BAB VII yang tertuang dalam Undang-undang Republik Indonesia Nomor 43 Tahun 2007 pasal 20 Tentang Perpustakaan, salah satunya adalah perpustakaan umum.

Perpustakaan umum memiliki berbagai layanan, Lasa (2007: 169) menyebutkan layanan perpustakaan merupakan upaya pemberdayaan yang berupa penyediaan jasa sirkulasi, layanan baca di tempat, pelayanan rujukan, penelusuran literatur, layanan anak, penyajian informasi terbaru, penyajian informasi terseleksi, pelayanan audio visual, pelayanan internet, bimbingan pemakai, jasa fotokopi, pelayanan reproduksi, pelayanan terjemahan, pelayanan pinjam antar perpustakaan, dan pelayanan konsultasi. Dari berbagai jenis layanan yang dikemukakan Lasa, masing-masing layanan memiliki tujuan dan fungsi yang berbeda. Meskipun memiliki tujuan dan fungsi yang berbeda, namun pustakawan tetaplah harus memiliki sikap pelayanan yang prima

\footnotetext{
${ }^{1}$ Mortimer, M. (2007). Library Speak: A Glossary of Terms in Librarianship and Information Management. First North American Edition. Texas: TotalRecall Publications.

${ }^{2}$ Lasa Hs. (2007). Manajemen Perpustakaan Sekolah. Yogyakarta: Pinus Book Publisher.
}

dalam melayani pemustaka. Dengan pelayanan yang baik, maka layanan-layanan yang ada di perpustakaan tersebut akan berjalan sesuai dengan rencana dan banyak pemustaka yang merasa puas dengan layanan serta pelayanan dari perpustakaan yang dikunjunginya.

Berdasarkan gagasan dari Parasuraman yang mendifenisikan tentang kualitas layanan sebagai suatu konsep secara tepat mewakili inti dari kinerja suatu pelayanan yaitu perbandingan terhadap keterhandalan (excellence) dalam service encounter yang dilakukan oleh konsumen. Berbeda dengan pendapat Parasuraman, Lovelock ${ }^{3}$ menyatakan bahwa kualitas pelayanan adalah tingkat keunggulan yang diharapkan dan pengendalian atas keunggulan tersebut untuk memenuhi harapan pelanggan. Sedangkan Bitner ${ }^{4}$ berpendapat bahwa kualitas pelayanan merupakan keseluruhan kesan konsumen terhadap inferioritas/ superioritas argumentasi beserta jasa yang ditawarkan. Parasuraman, et al. dalam penelitian awalnya mengidentifikasikan sepuluh dimensi pokok, yaitu reliabilitas, daya tanggap, kompetensi, akses, kesopanan, komunikasi, kredibilitas, keamanan, kemampuan memahami pelanggan dan bukti fisik. Parasuraman, et al. dalam

\footnotetext{
${ }^{3}$ Lovelock. (1988). Managing Service: Marketing, Operation, and Human Resources. London: Prentice-Hall International, Inc.

${ }^{4}$ Bitner, M. J. (1992). Servicescapes : The Impact of Physical surroundings on customers and employees. Journal of Marketing. Vol 56 No. 2, pp. 57-71

${ }^{5}$ Parasuraman, A., Zeithaml, V. A., Berry, L. L. (1988). Serqual A Multiple Item Scale For Measuring Consumer Perceptions Of Service Quality. Journal of Retailing, Vol: 64, No. 1 Spring, 1988

${ }^{6}$ Ibid
} 
penelitian selanjutnya merangkum kesepuluh dimensi tersebut menjadi lima dimensi kualitas pelayanan. Parasuraman et al. (1988) mengemukakan 22 item yang dipertimbangkan konsumen dalam mempersepsikan kualitas pelayanan, item tersebut dikelompokkan menjadi lima, yaitu: tangibles, reliability, responsiveness, assurance, dan empathy.

Perpustakaan Alternatif Wilayah Selatan Kota Yogyakarta atau yang kerap disebut dengan PEVITA merupakan salah satu perpustakaan yang ada di Kota Yogyakarta. Perpustakaan ini merupakan salah satu perpustakaan umum yang masih berdiri satu tahun. PEVITA adalah perpustakaan cabang dari Perpustakaan Kota Yogyakarta yang menginduk pada pemerintahan Kota Yogyakarta. PEVITA merupakan perpustakaan yang belum lama diresmikan. Perpustakaan ini terletak di bagian selatan Kota Yogyakarta, berlokasi di jalan Mayjend Sutoyo No.32, Mantrijeron, Kecamatan Mantrijeron, Kota Yogyakarta tepat di sebelah selatan Pojok Benteng Wetan Yogyakarta, berdirinya perpustakaan ini dengan tujuan untuk memberikan fasilitas/layanan kepada masyarakat agar masyarakat bagian selatan Kota Yogyakarta dapat mengakses perpustakaan kota yang lebih dekat dengan mereka. Di PEVITA menyediakan berbagai macam layanan, terdapat kurang lebih 30 layanan yang disediakan di perpustakaan mulai dari layanan koleksi buku cetak, layanan sirkulasi, layanan koleksi anak, layanan pengantaran buku koleksi ke pemustaka, dan masih banyak lagi layanan yang ada di perpustakaan ini.

Adapun terdapat alasan yang membuat peneliti melaksanakan penelitian di lokasi ini dikarenakan Perpustakaan Alternatif Wilayah Selatan Kota Yogyakarta merupakan perpustakaan yang menjalankan banyak program layanan, dan seluruh layanan tersebut diberikan nama-nama singkatan yang menarik agar pemustaka mudah mengingatnya. Peneliti lebih memilih PEVITA dibandingkan perpustakaan kota (induk Perpustakaan PEVITA) karena PEVITA merupakan perpustakaan yang baru diresmikan dibuka pada November 2018 di Yogyakarta yang didirikan khusus untuk masyarakat bagian selatan Kota Yogyakarta, dan hal ini menjadi tantangan tersendiri untuk perpustakaan yang baru saja dibuka dan bagaimana cara perpustakaan untuk membuat masyarakat tertarik agar datang ke perpustakaan. Hal tersebut menjadi daya tarik peneliti memilih Perpustakaan PEVITA ini. Berdasarkan uraian di atas, maka peneliti tertarik untuk melakukan penelitian mengenai analisis kualitas layanan perpustakaan Alternatif Wilayah Selatan Kota Yogyakarta.

\section{METODE PENELITIAN}

Desain yang digunakan dalam penelitian ini adalah penelitian kuantitatif deskriptif. Tujuan dalam penelitian ini adalah untuk mengetahui kualitas layanan pustakawan di Perpustakaan Alternatif Wilayah Selatan Kota 
Lia Yuliana dan Fauziah Khusnialli

Analisis Layanan Perpustakaan Alternatif

Wilayah Selatan Kota Yogyakarta dengan Model Servqual

Yogyakarta. Penelitian ini dilaksanakan di Perpustakaan Alternatif Wilayah Selatan Kota Yogyakarta yang beralamat di Jalan Mayjend Sutoyo No.32, Mantrijeron, Kecamatan Mantrijeron, Kota Yogyakarta, Daerah Istimewa Yogyakarta 55143. Waktu penelitian yang dilaksanakan oleh peneliti adalah selama tiga bulan dimulai dari bulan Maret 2020 hingga bulan Mei 2020. Instrumen penelitian menggunakan angket, kamera digital dan lembar observasi. Teknik pengumpulan data dengan cara observasi, penyebaran kuisioner dan dokumentasi. Indikator kualitas layanan pada penelitian ini menggunakan model servqual yang terdiri atas bukti fisik (tangibles), kehandalan (reliability), ketanggapan (responsiveness), jaminan (assurance), dan empati (empathy).

Populasi pada penelitian ini adalah seluruh pemustaka pada Perpustakaan Alternatif Wilayah Selatan Kota Yogyakarta. Populasi ini akan diambil dalam tiga bulan terakhir, yaitu bulan Oktober, sampai Desember tahun 2019 sejumlah 13.917 orang. Penulis membatasi jumlah populasi yang akan dijadikan sampel dengan menggunakan teknik probability sampling dengan cara simple random sampling dimana menentukan ukuran sampel dari populasi dengan menggunakan rumus Slovin. Hasil dari perhitungan rumus Slovin menemukan $\mathrm{n}$ (ukuran sampel) dengan penentuan sample mengambil presisi ditetapkan sebesar $10 \%$ dengan tingkat kepercayaan 90\%, maka uku- ran samplenya dapat ditetapkan sebagai berikut:

$$
\begin{gathered}
n=\frac{N}{1+N e^{2}} \\
n=\frac{4.639}{1+4.639(10 \%)^{2}}
\end{gathered}
$$

$\mathrm{n}=97,88$, dibulatkan menjadi 98.

Sedangkan untuk angket yang digunakan menggunakan skala Likert menggunakan bentuk checklist dalam menjawab pertanyaan/pernyataan instrument penelitian. Perhitungan persentase ini dilakukan dengan cara menjumlahkan skor perolehan yang dibagi dengan jumlah skor yang di harapkan, setelah itu hasil perhitungan dikalikan dengan $100 \%$.

\section{HASIL DAN PEMBAHASAN}

Pada hasil observasi dan hasil penelitian didapatkan Perpustakaan Alternatif Wilayah Selatan Kota Yogyakarta kondisinya tertata rapi, baik ruang baca, ruang koleksi anak, sirkulasi, serta area luar perpustakaan. Selanjutnya, dilakukan analisis kualitas layanan di perpustakaan Alternatif Wilayah Selatan Kota Yogyakarta berdasarkan model Servqual sebagai berikut:

\section{Bukti Fisik (Tangibles)}

Sub variabel bukti fisik memiliki empat indikator, diantaranya adalah gedung, perlengkapan dan peralatan, bahan pustaka, serta penampilan pustakawan. Berdasarkan hasil penelitian ini ditemukan bahwa kepuasan layanan pemustaka di Perpustakaan PEVITA dalam sub variabel bukti fisik (tangibles) 
menunjukkan bahwa skor total yang diperoleh adalah sebesar 4.497 atau $81 \%$ yang artinya adalah sub variabel bukti fisik (tangibles) termasuk dalam kategori cukup efektif.

Tabel 1. Hasil perhitungan item bukti fisik (tangi-

\begin{tabular}{|c|c|c|c|c|}
\hline \multicolumn{5}{|c|}{ bles) } \\
\hline No & Pernyataan & Skor & $\%$ & Kategori \\
\hline 1 & $\begin{array}{l}\text { Bangunan per- } \\
\text { pustakaan }\end{array}$ & 317 & $80 \%$ & $\begin{array}{l}\text { Cukup } \\
\text { Efektif }\end{array}$ \\
\hline 2 & $\begin{array}{l}\text { Fasilitas yang } \\
\text { disediakan per- } \\
\text { pustakaan }\end{array}$ & 305 & $77 \%$ & $\begin{array}{l}\text { Cukup } \\
\text { Efektif }\end{array}$ \\
\hline 3 & $\begin{array}{l}\text { Ruangan di per- } \\
\text { pustakaan }\end{array}$ & 355 & $90 \%$ & Efektif \\
\hline 4 & $\begin{array}{l}\text { Penerangan ru- } \\
\text { ang baca di per- } \\
\text { pustakaan }\end{array}$ & 351 & $89 \%$ & Efektif \\
\hline 5 & $\begin{array}{l}\text { Komputer yang } \\
\text { disediakan Per- } \\
\text { pustakaan }\end{array}$ & 325 & $82 \%$ & Efektif \\
\hline 6 & $\begin{array}{l}\text { Alat peraga } \\
\text { edukasi }\end{array}$ & 320 & $81 \%$ & $\begin{array}{l}\text { Cukup } \\
\text { Efektif }\end{array}$ \\
\hline 7 & $\begin{array}{l}\text { Kondisi rak bu- } \\
\text { ku/lemari buku } \\
\text { yang disediakan }\end{array}$ & 320 & $83 \%$ & Efektif \\
\hline 8 & $\begin{array}{l}\text { Koleksi bahan } \\
\text { pustaka di per- } \\
\text { pustakaan }\end{array}$ & 265 & $67 \%$ & $\begin{array}{l}\text { Cukup } \\
\text { Efektif }\end{array}$ \\
\hline 9 & $\begin{array}{l}\text { Ketersediaan } \\
\text { koleksi bahan } \\
\text { pustaka sesuai } \\
\text { dengan umur } \\
\text { pengguna }\end{array}$ & 311 & $79 \%$ & $\begin{array}{l}\text { Cukup } \\
\text { Efektif }\end{array}$ \\
\hline 10 & $\begin{array}{l}\text { Ketersediaan } \\
\text { koleksi bahan } \\
\text { pustaka sesuai } \\
\text { dengan yang } \\
\text { dibutuhkan } \\
\text { pengguna }\end{array}$ & 289 & $73 \%$ & $\begin{array}{l}\text { Cukup } \\
\text { Efektif }\end{array}$ \\
\hline 11 & $\begin{array}{l}\text { Koleksi bahan } \\
\text { pustaka selalu up } \\
\text { to date dan } \\
\text { mengikuti zaman }\end{array}$ & 299 & $76 \%$ & $\begin{array}{l}\text { Cukup } \\
\text { Efektif }\end{array}$ \\
\hline 12 & $\begin{array}{l}\text { Koleksi bahan } \\
\text { pustaka yang } \\
\text { disediakan } \\
\text { membantu dalam }\end{array}$ & 312 & $79 \%$ & $\begin{array}{l}\text { Cukup } \\
\text { Efektif }\end{array}$ \\
\hline
\end{tabular}

\begin{tabular}{|c|c|c|c|c|}
\hline No & Pernyataan & Skor & $\%$ & Kategori \\
\hline & $\begin{array}{l}\text { menyelesaikan } \\
\text { pekerjaan }\end{array}$ & & & \\
\hline 13 & $\begin{array}{l}\text { Penampilan } \\
\text { petugas per- } \\
\text { pustakaan }\end{array}$ & 359 & $91 \%$ & Efektif \\
\hline 14 & $\begin{array}{l}\text { Cara berpakaian } \\
\text { Karyawan/ } \\
\text { Satpam }\end{array}$ & 359 & $91 \%$ & Efektif \\
\hline \multicolumn{2}{|c|}{ Total } & 4.497 & $81 \%$ & $\begin{array}{l}\text { Cukup } \\
\text { Efektif }\end{array}$ \\
\hline
\end{tabular}

Bukti fisik adalah kemampuan perusahaan dalam menunjukkan penampilan fisik kepada konsumen, seperti penampilan fasilitas fisik, peralatan personel dan bahan komunikasi (Kotler dan Keller, 2009: 52). Aspek bukti fisik merupakan hal yang sangat memengaruhi penilaian pemustaka, karena semakin baik kualitas dari fasilitas-fasilitas yang ada di perpustakaan maka akan semakin tinggi tingkat kepuasan yang dimiliki pemustaka yang akan menjadikan hal tersebut efektif karena media yang digunakan dalam memenuhi kebutuhan terpenuhi dengan baik. Rahayuningsih (2015: 16) ${ }^{9}$ mengungkapkan bahwa suatu kepuasan dari pemustaka dipengaruhi oleh beberapa faktor, diantaranya adalah koleksi perpustakaan, fasilitas yang memadai, jenis jasa yang di berikan oleh perpustakaan serta bagaimana cara pustakawan memberikan pelayanan kepada pemustakanya. Apabila fasilitas yang tersedia di perpustakaan PEVITA terjada dengan baik dan tertata dengan rapi serta

\footnotetext{
${ }^{8}$ Kotler, P. \& Keller, K. L. (2009). Alih Bahasa: Benyamin Molan. Manajemen Pemasaran. Edisi Ketigabelas. Jilid 1. Cetakan Keempat. Jakarta: PT. Indeks.

${ }^{9}$ Rahayuningsih, F. (2015). Mengukur Kepuasan Pemustaka: Menggunakan Metode LibQUAL+TM. Yogyakarta: Graha Ilmu.
} 
Lia Yuliana dan Fauziah Khusnialli

Analisis Layanan Perpustakaan Alternatif

Wilayah Selatan Kota Yogyakarta dengan Model Servqual

kondisi pustakawannya yang mendukung, maka pemustaka akan merasa nyaman dan akan tertarik untuk berkunjung ke perpustakaan.

\section{Kehandalan (Reliability)}

Sub variabel kehandalan memiliki tiga indikator, diantaranya adalah ketepatan waktu, pelayanan yang sama rata, serta pemenuhan janji. Hasil penelitian ini menunjukan bahwa kemampuan perpustakaan dalam memberikan pelayanan sedemikian efektif mulai dari ketepatan jam buka layanan perpustakaan sesuai dengan jadwal yang telah ditetapkan, pembuatan kartu anggota yang mudah dan tidak memerlukan waktu lama, serta kemudahan yang diberikan dalam pelayanan hingga pelayanan yang diberikan pustakawan yang sama rata kepada pemustaka.

Tabel 2. Hasil perhitungan item kehandalan (relia-

\begin{tabular}{|l|l|c|c|c|}
\hline No & \multicolumn{1}{|c}{ Pernyataan } & Skor & $\%$ & Kategori \\
\hline 1 & $\begin{array}{l}\text { Petugas per- } \\
\text { pustakaan mem- } \\
\text { berikan pela- } \\
\text { yanan dengan } \\
\text { tepat }\end{array}$ & 352 & $89 \%$ & Efektif \\
\hline 2 & $\begin{array}{l}\text { Petugas per- } \\
\text { pustakaan cer- } \\
\text { mat dan teliti } \\
\text { ketika melayani } \\
\text { pengguna per- } \\
\text { pustakaan }\end{array}$ & 353 & $89 \%$ & Efektif \\
\hline 3 & $\begin{array}{l}\text { Petugas per- } \\
\text { pustakaan mem- } \\
\text { berikan pela- } \\
\text { yanan yang sa- } \\
\text { ma rata }\end{array}$ & 353 & $89 \%$ & Efektif \\
\hline 4 & $\begin{array}{l}\text { Petugas per- } \\
\text { pustakaan tidak } \\
\text { membeda- } \\
\text { bedakan } \\
\text { pengguna per- } \\
\text { pustakaan }\end{array}$ & 354 & $89 \%$ & Efektif \\
\hline
\end{tabular}

Berdasarkan hasil kehandalan adalah kemampuan perusahaan untuk memberikan pelayanan sesuai yang dijanjikan secara akurat dan terpercaya. Harus sesuai dengan harapan konsumen, yang berarti kinerja tepat waktu, pelayanan tanpa kesalahan, sikap simpatik, dan dengan akurasi tinggi ${ }^{10}$. Dari jam kunjung yang selalu tepat waktu seluai aturan, pembuatan kartu yang selesai dalam waktu maksimal satu jam, hingga perlakuan yang sama rata kepada seluruh pemustaka tanpa membeda-bedakan. Berdasarkan pendapat Barata $^{11}$ memberikan layanan yang terbaik dapat terwujud apabila kita menampakkan kemampuan, sikap, penampilan, perhatian, tindakan, serta tanggung jawab yang baik dan terkoordinasi. Dari pendapat tersebut, petugas perpustakaan sangat menonjolkan pelayanannya yang terbaik agar pemustaka tidak merasa kecewa dengan pelayanan perpustakaan di PEVITA.

\footnotetext{
${ }^{10}$ Ratnasari, R. T. \& Aksa, M. H. (2011). Teori dan Kasus Manajemen Pemasaran Jasa. Bogor: Ghalia Indonesia.

${ }^{11}$ Barata, A. A. (2003). Dasar-Dasar Pelayanan Prima. Jakarta : Elex Media Kompetindo.
} 


\section{Ketanggapan (Responsiveness)}

Sub variabel ketanggapan (responsiveness) memiliki dua indikator, yaitu kesigapan pustakawan serta kecepatan pustakawan. Dari dua indikator tersebut terbagi menjadi 4 pemyataan. keefektifan layanan di perpustakaan PEVITA dalam sub variabel ketanggapan (responsiveness) menunjukkan bahwa skor total keefektifan adalah sebesar 1.418 atau 90\% yang artinya adalah sub variabel ketanggapan (responsiveness) termasuk dalam kategori sangat puas. Hal ini menunjukan bahwa dengan sikap tanggap yang dimiliki petugas perpustakaan, pemustaka merasa terbantu dalam menggunakan layanan perpustakaan.

Tabel 3. Hasil perhitungan item ketanggapan ( $r e-$

\begin{tabular}{|l|l|c|c|c|}
\hline No & \multicolumn{1}{|c}{ Pernyataan } & Skor & $\%$ & Kategori \\
\hline 1 & $\begin{array}{l}\text { Petugas per- } \\
\text { pustakaan sigap } \\
\text { apabila ada } \\
\text { keluhan maupun } \\
\text { kesulitan dalam } \\
\text { memanfaatkan } \\
\text { layanan per- } \\
\text { pustakaan. }\end{array}$ & 360 & $91 \%$ & Efektif \\
\hline 2 & $\begin{array}{l}\text { Petugas per- } \\
\text { pustakaan tang- } \\
\text { gap untuk mem- } \\
\text { bantu pengguna } \\
\text { perpustakaan }\end{array}$ & 356 & $90 \%$ & Efektif \\
\hline 3 & $\begin{array}{l}\text { Petugas per- } \\
\text { pustakaan siap } \\
\text { dan bersedia } \\
\text { membantu } \\
\text { pengguna per- } \\
\text { pustakaan } \\
\text { dengan cepat }\end{array}$ & 354 & $89 \%$ & Efektif \\
\hline 4 & $\begin{array}{l}\text { Petugas per- } \\
\text { pustakaan berge- } \\
\text { rak cepat ketika } \\
\text { pengguna per- } \\
\text { pustakaan mem- } \\
\text { butuhkan bantu- } \\
\text { an }\end{array}$ & 348 & $88 \%$ & Efektif \\
\hline
\end{tabular}

\begin{tabular}{|l|c|c|c|c|}
\hline No & Pernyataan & Skor & $\%$ & Kategori \\
\hline Total & & 1.418 & $90 \%$ & Efektif \\
\hline
\end{tabular}

Ratnasari dan Aksa (2011: 108) ${ }^{12}$ berpendapat bahwa ketanggapan merupakan suatu kemauan untuk membantu dan memberikan pelayanan yang cepat dan tepat kepada pelanggan, dengan penyampaian informaasi yang jelas. Membiarkan pemustaka menunggu tanpa alasan yang jelas, meyebabkan persepsi yang negatif dalam kualitas jasa. Sikap tanggap dari pustakawan akan memberikan penilaian yang baik terhadap tingkat kepuasan pemustaka, karena masalah-masalah yang ditemui pemustaka dalam menggunakan layanan perpustakaan akan terpecahkan dengan bantuan yang diberikan oleh pustakawan. Contoh dari sub variabel ketanggapan misalnya, petugas perpustakaan sigap apabila ada keluhan maupun kesulitan yang dialami pemustaka dalam memanfaatkan layanan perpustakaan. Petugas tanggap untuk membantu pemustaka, petugas siap dan bersedia membantu pemustaka dengan cepat, serta petugas bergerak cepat ketika pemustaka membutuhkan bantuan. Barata $^{13}$ mengatakan bahwa pelayanan perpustakaan yang prima merupakan kepedulian perpustakaan kepada pemustaka dengan memberikan layanan yang terbaik untuk memfasilitasi kemudahan pemenuhan kebutuhan serta mewujudkan kepuasannya, agar mereka selalu loyal kepada perpustakaan.

\section{Jaminan (Assurance)}

\footnotetext{
${ }^{12}$ Ratnasari \& Aksa, Op.cit hlm. 6

${ }^{13}$ Barata, A. A., Loc.cit
} 
Lia Yuliana dan Fauziah Khusnialli

Analisis Layanan Perpustakaan Alternatif

Wilayah Selatan Kota Yogyakarta dengan Model Servqual

Variable ini terdiri dari beberapa komponen antara lain komunikasi (communication), keamanan (security), kompetensi (competence), dan sopan santun (courtesy). Pada penelitian ini, dari tiga indikator tersebut terbagi menjadi 9 pernyataan. Hasil menunjukkan cukup efektif dengan $81 \%$. Hal ini menggambarkan bahwa pelayanan yang diberikan oleh perpustakaan berdasarkan jaminan atau keyakinan yang diberikan petugas perpustakaan dalam memberikan pelayanan sudah memberikan pada pemustaka, hal ini menunjukan bahwa pemustaka memiliki rasa kepercayaan yang baik dengan pelayanan yang diberikan Perpustakaan PEVITA dan menjadikan perpustakaan sebagai tempat untuk mencari informasi yang pemustaka butuhkan.

Tabel 5. Hasil perhitungan item jaminan (assur-

\begin{tabular}{|l|l|c|c|c|}
\hline No & \multicolumn{1}{|c}{ Pernyataan } & Skor & $\%$ & Kategori \\
\hline 1 & $\begin{array}{l}\text { Petugas per- } \\
\text { pustakaan } \\
\text { mengabaikan } \\
\text { kritik dan saran } \\
\text { dari pengguna }\end{array}$ & 231 & $58 \%$ & $\begin{array}{c}\text { Kurang } \\
\text { Efektif }\end{array}$ \\
\hline 2 & $\begin{array}{l}\text { Petugas per- } \\
\text { pustakaan me- } \\
\text { nanggapi } \\
\text { kemauan dari } \\
\text { pengguna per- } \\
\text { pustakaan }\end{array}$ & 325 & $82 \%$ & Efektif \\
\hline 3 & $\begin{array}{l}\text { Terjalin komu- } \\
\text { nikasi antara } \\
\text { petugas per- } \\
\text { pustakaan } \\
\text { dengan } \\
\text { pengguna per- } \\
\text { pustakaan }\end{array}$ & 328 & $83 \%$ & Efektif \\
\hline 4 & $\begin{array}{l}\text { Sikap sopan } \\
\text { petugas per- } \\
\text { pustakaan dalam } \\
\text { melayani } \\
\text { pengguna per- } \\
\text { pustakaan }\end{array}$ & 351 & $89 \%$ & Efektif \\
\hline
\end{tabular}

\begin{tabular}{|l|l|c|c|c|}
\hline No & \multicolumn{1}{|c|}{ Pernyataan } & Skor & \% & Kategori \\
\hline 5 & $\begin{array}{l}\text { Sikap ramah } \\
\text { petugas per- } \\
\text { pustakaan kepa- } \\
\text { da pengguna } \\
\text { perpustakaan }\end{array}$ & 355 & $90 \%$ & Efektif \\
\hline 6 & $\begin{array}{l}\text { Petugas } \\
\text { tersenyum ketika } \\
\text { melayani } \\
\text { pengguna per- } \\
\text { pustakaan }\end{array}$ & 334 & $84 \%$ & Efektif \\
\hline 7 & $\begin{array}{l}\text { Barang yang } \\
\text { dititipkan diloker } \\
\text { terjamin keama- } \\
\text { nannya }\end{array}$ & 313 & $79 \%$ & $\begin{array}{l}\text { Cukup } \\
\text { Efektif }\end{array}$ \\
\hline 8 & $\begin{array}{l}\text { Kendaraan ter- } \\
\text { jamin } \\
\text { keamanannya di } \\
\text { area parkir per- } \\
\text { pustakaan }\end{array}$ & 354 & $89 \%$ & Efektif \\
\hline 9 & $\begin{array}{l}\text { Jaminan atas } \\
\text { kehilangan ba- } \\
\text { rang pribadi }\end{array}$ & 298 & $75 \%$ & $\begin{array}{l}\text { Cukup } \\
\text { Efektif }\end{array}$ \\
\hline Total & 2.889 & $81 \%$ & $\begin{array}{l}\text { Cukup } \\
\text { Efektif }\end{array}$ \\
\hline
\end{tabular}

Jaminan adalah pengetahuan, kesopansantunan dan kemampuan para pegawai perusahaan untuk menumbuhkan rasa percaya para konsumen kepada perusahaan yang meliputi: pengetahuan, kemampuan, kesopanan dan sifat dapat dipercaya yang dimiliki staf, bebas dari bahaya, resiko dan keraguraguan ${ }^{14}$. Selain itu menurut pendapat Ratnasari dan Aksa ${ }^{15}$ jaminan atau kepastian adalah pengetahuan, kesopanan, dan kemampuan para pegawai perusahaan untuk menumbuhkan rasa percaya konsumen kepada perusahaan. Terdiri atas komponen: komunikasi, kredibilitas, keamanan, kompetensi, dan sopan santun. Berdasarkan hasil pengecekan, komunikasi yang

\footnotetext{
${ }^{14}$ Suryani, T. (2013). Perilaku Konsumen di Era Internet Implikasinya pada Strategi Pemasaran. Edisi Pertama.Yogyakarta: Graha Ilmu

${ }^{15}$ Ratnasari \& Aksa, Op.cit hlm. 6
} 
terjalin antara pustakawan dengan pemustaka sangat kuat dan pustakawan tidak mengabaikan kritik dan saran yang disampaikan oleh pemustaka. Kritik dan saran yang disampaikan selalu diterima dengan terbuka, bahkan kritik maupun saran tersebut akan dijawab oleh pihak perpustakaan dengan cara dipajang (ditempel) pada papan alternatif SASKIA (Sabtu Seru di Perpus Kota).

\section{Empati (Empathy)}

Sub variabel empati (empathy) memiliki satu indikator, yaitu indikator kemampuan pustakawan dalam memahami pustakawan. Berdasarkan tabel 6, dapat dikatakan bahwa pelayanan yang diberikan oleh perpustakaan yang meliputi aspek empati melalui pelayanan pustakawan dalam memberikan pelayanan sudah sangat memuaskan bagi pemustaka, hal ini menunjukan bahwa perhatian tulus yang diberikan kepada para pemustaka dengan berupaya memahami keinginan mereka sudah tercapai dengan efektif.

Tabel 6. Hasil perhitungan item empati (empathy)

\begin{tabular}{|l|l|c|c|c|}
\hline No & \multicolumn{1}{|c|}{ Pernyataan } & Skor & $\%$ & Kategori \\
\hline 1 & $\begin{array}{l}\text { Petugas me- } \\
\text { mahami keingi- } \\
\text { nan pengguna } \\
\text { perpustakaan }\end{array}$ & 329 & $83 \%$ & Efektif \\
\hline 2 & $\begin{array}{l}\text { Petugas per- } \\
\text { pustakaan mem- } \\
\text { berikan arahan } \\
\text { dan bimbingan } \\
\text { dalam mencari } \\
\text { informasi di Per- } \\
\text { pustakaan }\end{array}$ & 337 & $85 \%$ & Efektif \\
\hline \multicolumn{2}{|l|}{ Total } & 666 & $84 \%$ & Efektif \\
\hline
\end{tabular}

Menurut Tjiptono ${ }^{16}$ suatu lembaga memahami masalah para pelanggannya dan bertindak demi kepentingan pelanggan, serta memberikan personal kepada para pelanggan dan memiliki jam operasi yang nyaman. Sedangkan menurut Parasuraman ${ }^{17}$ yang mengatakan bahwa setiap kegiatan atau aktivitas pelayanan memerlukan adanya pemahaman dan pengertian dalam kebersamaan asumsi atau kepentingan terhadap suatu hal yang berkaitan dengan pelayanan. Pelayanan akan berjalan dengan lancar dan berkualitas apabila setiap pihak yang berkepentingan dengan pelayanan memiliki adanya rasa empati atau perhatian dalam menyelesaikan atau mengurus atau memiliki komitmen yang sama terhadap pelayanan.

Empati dalam suatu pelayanan adalah adanya suatu perhatian, keseriusan, simpatik, pengertian dan keterlibatan pihak-pihak yang berkepentingan dengan pelayanan untuk mengembangkan dan melakukan aktivitas pelayanan sesuai dengan tingkat pengertian dan pemahaman dari masing-masing pihak tersebut. Pihak yang memberi pelayanan harus memiliki empati memahami masalah dari pihak yang ingin dilayani. Pihak yang dilayani seyogyanya memahami keterbatasan dan kemampuan orang yang melayani, sehingga keterpaduan antara pihak yang melayani dan mendapat pelayanan memiliki perasaan yang sama. Sikap empati yang diberikan per-

\footnotetext{
${ }^{16}$ Tjiptono, F. (2012). Service Management Mewujudkan Layanan Prima. Yogyakarta: Andi

${ }^{17}$ Parasuraman, Op.cit hlm. 3
} 
Lia Yuliana dan Fauziah Khusnialli

Analisis Layanan Perpustakaan Alternatif

Wilayah Selatan Kota Yogyakarta dengan Model Servqual

pustakaan terhadap pemustaka akan membuat mereka merasa nyaman menggunakan perpustakaan karena pemustaka merasa kebutuhannya dalam mencari informasi dapat terpenuhi dan akan menimbulkan feedback yang positif dari pemustaka sehingga perpustakaan akan ramai dikunjungi. Sikap empati sangat bergantung pada moral kerja masing-masing individu pustakawan, dalam hal ini pustakawan harus bersikap mau mengerti pemustaka dan menghilangkan sikap ego yang dimilki oleh masing-masing pustakawan sehingga terwujudnya susana yang kondusif dan mendukung dalam mencapai tujuan perpustakaan, ${ }^{18}$ menjelaskan bahwa moral kerja yang tinggi akan menaikkan produktivitas, artinya seseorang yang memiliki moral kerja yang tinggi akan mengerjakan tugas-tugasnya dengan sebaik-baiknya sehingga menghasilkan sesuatu yang lebih banyak dan lebih baik.

Pada penelitian yang dilakukan oleh peneliti ini, sama halnya dengan penelitian terdahulu yang dilakukan oleh Nur Dwi Jayanti $(2016)^{19}$ mengenai Kualitas Pelayanan di Legend Premium Coffee menunjukkan bahwa keseluruhan kualitas pelayanan di Lengend Premium Coffee Yogyakarta dari segi kualitas jasa dilihat dari jawaban responden terhadap

\footnotetext{
${ }^{18}$ Darmono. (2001). Manajemen \& Tata Kerja Perpustakaan Sekolah. Jakarta: Grasindo.

${ }^{19}$ Jayanti, N. D. (2016). Kualitas Pelayanan (Reliability, Responsiveness, Assurance, Emphaty, Tangibles) di Legend Premium Coffee Yogyakarta. Skripsi. Yogyakarta: Fakultas Teknik Universitas Negeri Yogyakarta.
}

pernyataan/ item yang telah diajukan oleh peneliti tersebut termasuk dalam kategori baik dan cukup baik. Akan tetapi masih banyak pelayanan yang diberikan oleh pelayan yang harus diperbaiki lagi, diantaranya pelayanan yang lebih profesional, pelayanan secara prima dengan kecekatan pelayan saat memberikan jasa, sopan dan ramah ketika memberikan pelayanan. Hal ini perlu diperhatikan lagi agar konsumen merasa nyaman dan loyal terhadap jasa yang diberikan. Hal itu serupa dengan penelitian ini, pada keseluruhan kualitas pelayanan terdapat pada kategori baik, namun masih terdapat beberapa hal yang perlu diperhatikan pada beberapa aspek seperti penyediaan buku-buku baru, promosi untuk menarik pengunjung, komunikasi yang terjalin antara pemustaka dengan pustakawan, serta rasa aman yang dirasakan oleh pemustaka ketika menggunakan perpustakaan. Sedangkan pada penelitian lain, oleh Fadhli, dkk. (2020: 78) ${ }^{20}$ disebutkan pustakawan membangun hubungan mendalam dengan pemustaka sehingga mengenal konsumennya dengan baik. Selanjutnya pustakawan dapat terbantu dalam memenuhi kebutuhan pemustaka dalam proses layanan yang optimal.

Hasil penelitian pada keseluruhan kualitas layanan yang didapat sejalan dengan pendapat Ririn Tri Ratnasari dan Mastuti Aksa bahwa

\footnotetext{
${ }^{20}$ Fadhli, R., Indah, R. N., Widya, N., \& Oktaviani, W. (2020). Strategi Perpustakaan Sekolah Dasar Dalam Mengembangkan Emotional Branding Melalui Storytelling. JMIE (Journal of Madrasah Ibtidaiyah Education), 4(1), 68-85.
} 
kualitas layanan pada industri jasa adalah mutlak bahwa pelanggan akan merasa puas bila mereka mendapatkan pelayanan yang baik atau sesuai dengan yang pelanggan harapkan. Serta pendapat Kotler dan Keller yang menyarankan untuk memperkecil kesenjangan yang terjadi antara pihak manajemen dan pelanggan, misalnya dengan melakukan penelitian dengan metode customer focus, dengan mengedarkan kuesioner dalam beberapa periode untuk mengetahui persepsi pelayanan menurut pelanggan. Selain itu, juga dilakukan pengamatan dan pengawasan pegawai perusahaan tentang pelaksanaan pelayanan.

\section{KESIMPULAN}

Berdasarkan hasil penelitian dan pembahasan mengenai keefektifan layanan koleksi anak yang dilaksanakan di Perpustakaan PEVITA, tanggapan responden dalam penelitian ini berada pada kategori "sangat puas" dengan nilai persentase keefektifan layanan koleksi anak sebesar $84 \%$. Keefektifan layanan tersebut dihitung dengan menggunakan lima sub variabel. Sub variabel Bukti fisik (tangibles) memiliki skor persentase sebesar $81 \%$ yang artinya termasuk dalam kategori puas. Kemudian sub variabel kehandalan (reliability) mendapatkan skor persentase sebesar $89 \%$ masuk dalam kategori sangat puas. Selanjutnya adalah sub variabel ketanggapan (responsiveness) dengan perolehan persentase tertinggi sebesar $90 \%$ yang artinya sub variabel ter- sebut sangat puas. Selain itu sub variabel jaminan (assurance) dengan total skor persentase $81 \%$ yang dikategorikan puas. Terakhir adalah sub variabel empati (empathy) dengan hasil persentase $84 \%$ yang berarti sub variabel tersebut sangat puas.

\section{Daftar Pustaka}

Barata, A. A. (2003). Dasar- Dasar Pelayanan Prima. Jakarta : Elex Media Kompetindo.

Bitner, M. J. (1992). Servicescapes : The Impact of Physical surroundings on customers and employees. Journal of Marketing. Vol 56 No. 2, pp. 57-71

Darmono. (2001). Manajemen \& Tata Kerja Perpustakaan Sekolah Jakarta: Grasindo.

Dekdikbud. (2013).Undang-undang RI Nomor 32 Tahun 2013 tentang Perubahan atas Undang-undang Nomor 19 Tahun 2005 tentang Standar Nasional Pendidikan. Jakarta: Sekretariat Negara.

Fadhli, R., Indah, R. N., Widya, N., \& Oktaviani, W. (2020). Strategi Perpustakaan Sekolah Dasar Dalam Mengembangkan Emotional Branding Melalui Storytelling. JMIE (Journal of Madrasah Ibtidaiyah Education), 4(1), 68-85.

Jayanti, N. D. (2016). Kualitas Pelayanan (Reliability, Responsiveness, Assurance, Emphaty, Tangibles) di Legend Premium Coffee Yogyakarta. Skripsi. Yogyakarta: Fakultas Teknik Universitas Negeri Yogyakarta.

Kotler, P. \& Keller, K. L. (2009). Alih Bahasa: Benyamin Molan. Manajemen Pemasaran. Edisi Ketigabelas. Jilid 1. Cetakan Keempat Jakarta: PT. Indeks. 
Lia Yuliana dan Fauziah Khusnialli Analisis Layanan Perpustakaan Alternatif Wilayah Selatan Kota Yogyakarta dengan Model Servqual

Lasa Hs. (2007). Manajemen Perpustakaan Sekolah. Yogyakarta: Pinus Book Publisher.

Lovelock. (1988). Managing Service: Marketing, Operation, and Human Resources. London: Prentice-Hall International, Inc.

Mortimer, M. (2007). Library Speak: A Glossary of Terms in Librarianship and Information Management. First North American Edition Texas: TotalRecall Publications.

Parasuraman, A., Zeithaml, V. A., Berry, L. L. (1988). Serqual A Multiple Item Scale For Measuring Consumer Perceptions Of Service Quality. Journal of Retailing, Vol: 64, No. 1 Spring, 1988.

Rahayuningsih, F. (2015). Mengukur Kepuasan Pemustaka: Menggunakan Metode LibQUAL+TM. Yogyakarta: Graha Ilmu.

Ratnasari, R. T. \& Aksa, M. H. (2011). Teori dan Kasus Manajemen Pemasaran Jasa. Bogor: Ghalia Indonesia.

Suryani, T. (2013). Perilaku Konsumen di Era Internet Implikasinya pada Strategi Pemasaran. Edisi Pertama.Yogyakarta: Graha Ilmu

Tjiptono, F. (2012). Service Management Mewujudkan Layanan Prima. Yogyakarta: Andi 